welcome from general students of climate and weather. When the contents of that summary happen to be right up to date, lucid and remarkably comprehensive, the welcome is doubly assured. Here, let it be said straight away, is a safe inexpensive guide for all interested in the fundamentals of climatology and an indispensable companion for the student of the more aerial aspects of earth sciences. The authors, who hail from Southampton and Cambridge, have wisely assumed that their readers have some knowledge and still prefer literature to logarithmic tables. Consequently their text is pleasantly readable. Yet their discussions are scientifically convincing, for they make regular use of simple equations, and where the quantities and proportions involved become rather elaborate they are expressed also in diagrammatic form. There are about 150 of these explanatory diagrams, which in themselves are worth the purchaso price. In addition there are twenty-eight plates, mostly of the atmosphere with its cloud formations photographed from spacecraft. These are a delight and demonstrate vividly how much weather study is benefiting from spaco projects.

The text consists of eight main chapters of which the first four cover basic meteorological processes and concepts. These deal respectively with the nature of the atmosphere and its energy sources, transfers and budget; atmospheric moisture; atmospheric motion; and air masses, fronts and depressions. The approach is causal and practical. Thus the account of precipitation processes is followed by a discussion of precipitation characteristics and types; and that of atmospheric motions includes inter alia Coriolis force, local winds, upper winds and major wind systems.

The next two chapters deal with regional climatology and summarize climatic characteristics on the basis of meteorological conditions. In the fifth chapter on "temperate latitude" climates, the authors are concerned principally with Europe and North America which, no doubt, will be very suitable for university courses, but seems rather neglectful of the Soviet Union, whose writers are often referred to elsewhere in this text. The sixth chapter, on the tropical airspace, emphasizes the falsity of an assumed simplicity of tropical weather and adds a substantial account of the Asian monsoon. In the seventh chapter the authors chose urban climates and forest. climates to exemplify in detail the main principles of microclimatology. The eighth chapter contains a concise analysis of climatic variability, trends and fluctuations, ono of the most popular themes in modern meteorology. There follow an excellent bibliography which will suffice for any student, and a bibliographed, illustrated appendix on climatic classification.

This splendid little book will immediately become a popular, recommended text and will go into many editions. For those reasons, it must be made the object of a minor point of adverse criticism that could equally be applied to many other modern climatological texts. In the next edition the authors must jettison the use of Mercator's cylindrical projection, one of the greatest menaces and most misleading devices ever foisted on innocent meteorologists. The diagrams (on the Mercator graticule) of mean daily shade air temperatures (pago 37), world mean sea-level air temperatures (pages 38 and 39 ), and of ternperature anomalies (pages 44 and 45 ) are in fact takon direct from eminent meteorological sources but we expect something better of scientific geographers. Mercator's cylindrical graticule is worse than useless for such purposes and its deviser has probably done more harm to moteorology than any other single author. It is largely responsible for the general non-appreciation of the areal and still greater volumetric smallness of the airspace outside of latitudes $60^{\circ}$ or conversely for the lack of appreciation of the tremendous spatial and volumetric dominance of the tropical scene. The praiseworthy diagrams of, for example, mean global precipitation (pages 96 and 97) and world climatic classification (page 299) demonstrate that €qual-area graticules are essential for world distributions. Use Hammer-Aitoff or Mollweide, but Mercator never!

RoBert P. Bechinsale

\section{ADVANCING CONTROL}

Advances in Control Systems: Theory and Applications Edited by C. T. Leondes. Volume 5. Pp. xii +426. (New York: Academic Press, Inc. ; London: Academic Press, Inc. (London), Ltd., 1967.) 148s.

Conтrol systems science is at an ambiguous stage in its development. No longer exclusively wedded to technology, it is moving, legitimately, to problems of mathematical interest. These include the qualitative properties of differential equations (stability, controllability, reachable set theory); probability theory (evolution of conditional probability densities, representation of stochastic integrals and equations, optimal control of stochastic processes); mathematical programming (numerical algorithms for optimization of deterministic and stochastic systems described by ordinary or partial differential equations, mathematical programming in function space) and statistics (estimation of parameters). This partial selection is sufficient to show the need for the co-operation of mathematicians in this field. On the other hand, there are many technological problems which are being studied. The inherent danger facing the subject, however, is that it may become the study of proposed systems or techniques for control which, though complex, are neither sufficiently fundamental to lead to a development in mathematics, nor sufficiently practical to be useful technologically.

This new volume in the series of "Advances in Control Systems, Theory and Applications" is, like its predecessors, a collection of long articles on specialist subjects, at least several of which are condensations of doctoral theses. Consider first two articles of potential interest to both mathematicians and control engineers. The article by Snow considers the problem of finding the set of states that can bo replaced at time $T$ by the use of controls belonging to a given class. A Hamilton-Jacobi partial differential equation, which describes the evolution of the reachable set, is obtained. A rigorous proof of the existence of various limits is not given. The results, however, are true for a sub-class of singular problems, for which a rigorous treatment is given. The second article, by Fisher, deals with the filtering of processes described by non-linear stochastic differential equations. The article is very extensive; however, the treatment is purely formal, and in view of the complexity of the problem, most readers will wish to refer to the original articles by Wonham and Kushner.

The next two articles deal with numerical methods. Scharmack gives a more thorough discussion than usual of the by now well known boundary-iteration method of determining an optimal trajectory and presents numerical results for a re-entry path problem. He includes a problem with a state-variable constraint, which is also the subject of the article by McIntyre and Paiewonsky. This is a pleasant, informal discussion of the numerical difficulties arising in state-constrained problems, and will bo appreciated by those approaching this difficult topic.

The article by Wiberg deals with optimal control of nuclear reactor systems. The inclusion of specialist articles dealing with a specific technology is to bo commended.

Finally, there is an interesting article by Pearson. describing an approach, largely due to the author, of determining the optimal steady state control of a process with unknown dynamies. The adaptive control problem, however, has absorbed much effort, with little practical achievement, and the utility of the approach remains to be assessed.
D. Q. MAYNE 